\section{ENTREVISTA: SÉRGIO AROUCA}

INTERVIEW: SÉRGIO AROUCA
Antônio Sérgio da Silva Arouca nasceu em Ribeirão Preto e formou-se médico pela Universidade de São Paulo (USP), em 1966. Como consultor da Organização Pan-Americana de Saúde (OPAS), atuou em vários países. Arouca ocupou a Presidência da Fiocruz de 1985 a 1988, na qual comandou o processo de democratização da instituição. Concorreu à Vice-Presidência da República pelo Partido Comunista Brasileiro (PCB). Arouca foi deputado federal por dois mandatos e ocupou diversos cargos em comissões de saúde, ciência e tecnologia. Como deputado federal, participou da criação do Sistema Único de Saúde (SUS), nos anos 80. Presidiu a VIII Conferência Nacional de Saúde, em 1986, um marco na concepção do sistema de saúde brasileiro. Em janeiro do corrente ano, assumiu a Secretaria de Gestão Participativa do Ministério da Saúde, tendo sido nomeado representante do Brasil na Organização Mundial de Saúde (OMS) e indicado para a coordenação-geral da XII Conferência Nacional de Saúde. Faleceu em 2 de agosto de 2003.

$\mathrm{Na}$ entrevista concedida à revista Radis, da Fundação Oswaldo Cruz, em outubro de 20021, Arouca discute, entre outros temas, a falência do SUS como modelo assistencial, a prática da medicalização, as políticas industrial e científica no campo da saúde e, sobretudo, a história e os princípios básicos da Reforma Sanitária.
Antônio Sérgio da Silva Arouca was born in Ribeirão Preto (SP) and graduated in Medicine by the University of São Paulo (USP) in 1966. In his role as consultant for the Pan-American Health Organization he worked in several countries. Arouca was Head of the Oswaldo Cruz Foundation (Fiocruz) from 1985 to 1988 and under his direction the institution embarked in a successful process of democratization. He was the Brazilian Communist Party's candidate to the Vice-Presidency of Brazil. Arouca was federal deputy for two consecutive terms and occupied several positions in various health, scientific and technological commissions. As federal deputy, he took part in the founding of the Brazilian Health System (SUS) in the 80s. In 1986, he presided over the VIII National Conference on Health, a landmark in the concept of the Brazilian health system. In January this year he took over the Secretariat of Participatory Management of the Brazilian Health Ministry, was nominated Brazilian representative in the World Health Organization (WHO) and for the post of General Coordinator of the XII National Conference on Health. He died on 2 nd August 2003.

In the interview granted to the magazine Radis, of the Oswaldo Cruz Foundation, in October 20021, Arouca discusses, among other issues, the failure of the SUS as a welfare model, the practice of medicalization, industrial and scientific policies in the health area and, most importantly, the history and the basic principles of the Sanitary Reform. 


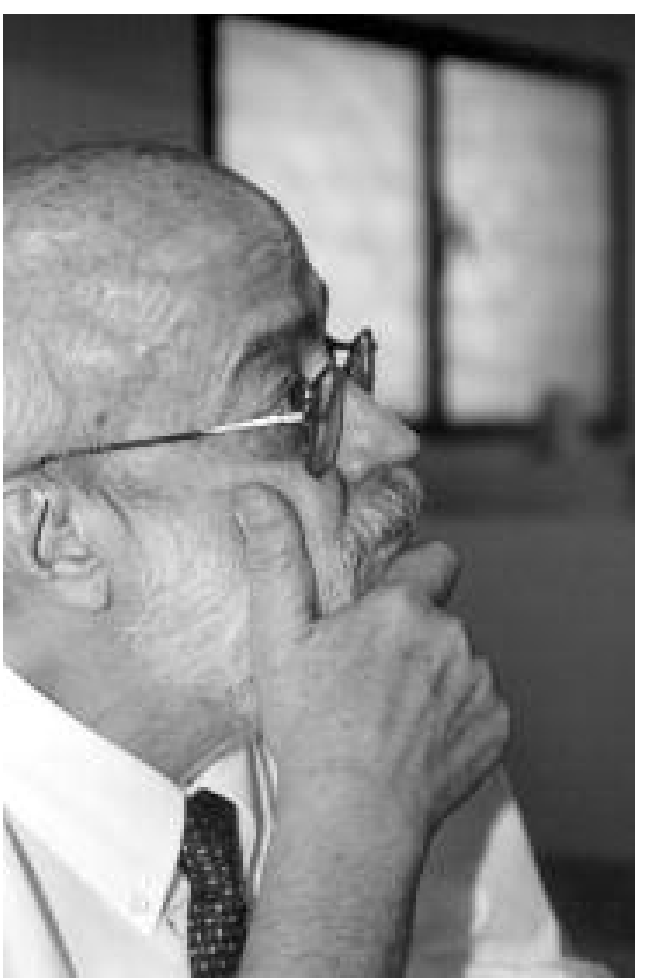

foto: Peter Illicciev

Radis

A Saúde Pública mudou nesses últimos anos, quando muitas questões sociais e estruturais foram adicionadas ao seu contexto. Em relação a essas mudanças, e mais de uma década depois da implantação do Sistema Único de Saúde (SUS), tem sentido ainda falar em Reforma Sanitária?

\section{Sérgio Arouca}

A pergunta tem a ver com a origem do movimento da Reforma Sanitária, com a passagem do pensamento crítico para uma proposta de ação. O movimento da Reforma Sanitária nasceu dentro da perspectiva da luta contra a ditadura, da frente democrática, de realizar trabalhos onde existiam espaços institucionais. $\mathrm{Na}$ área da saúde, existia a idéia clara de que não poderíamos fazer disso uma esquizofrenia, ser médico e lutar contra a ditadura. Era preciso integrar essas duas dimensões.
O espaço para essa integração era o da Medicina Preventiva, movimento recém-criado no Brasil, que começou na Escola Paulista de Medicina, em Ribeirão Preto, e na Universidade Federal do Rio de Janeiro (UFRJ). A idéia era que o Sistema de Saúde não precisava mudar em na$\mathrm{da}$, que se poderia deixar as clínicas privadas e planos de saúde como estavam e que bastava mudar a mentalidade do médico. O movimento da Reforma Sanitária cria uma outra alternativa, que se abria para uma análise de esquerda marxista da saúde, na qual se rediscute o conceito saúde/doença e o processo de trabalho, em vez de se tratar apenas da relação médico/paciente. Discute-se a determinação social da doença e se introduz a noção de estrutura de sistema.

Começamos a fazer projetos de saúde comunitária, como clínica de família e pesquisas comunitárias, e fizemos treinamento do pessoal que fazia política em todo o Brasil. No PCB, havia uma dinâmica para o debate sobre saúde. Quando a ditadura chegou ao seu esgotamento, o movimento já tinha propostas. Não só criou quadros de profissionais, mas também meios de comunicação, espaço acadêmico consolidado, movimento sindical estruturado e muitas práticas. Assim, esse movimento conseguiu se articular em um documento chamado Saúde e Democracia, que foi um grande marco, e enviá-lo para aprovação do Legislativo. Nós queríamos conquistar a democracia para então começar a mudar o sistema de saúde, porque tínhamos muito claro que ditadura e saúde são incompatíveis. Nosso primeiro movimento era, portanto, no sentido de derrubar a ditadura, e não de melhorar a saúde. Tudo isso aconteceu antes da Constituinte.

\section{Radis}

O panorama, nessa época, parecia favorável a essas mudanças?

\section{Sérgio Arouca}

Nessa época, eu me torno presidente da Fundação Oswaldo Cruz, o Hésio Cordeiro se torna presidente do Inamps, Renato Archer começa a atuar na Ciência e Tecnologia e Waldir Pires assume a Previdência Social. Há um núcleo de pensamento da esquerda em conflito com um núcleo conservador. Carlos Santana, que ideologicamente era considerado conservador, mas que era um radical na área da saúde, se torna Ministro da Saúde. Começa aí a discussão em torno do primeiro passo a ser dado. O marco era 
transferir o Inamps para o Ministério da Saúde, e qualquer reforma deveria começar pela integração. Mas havia um problema: a Saúde estava na mão de um conservador e a Previdência com a oposição. Até que, na calada da noite, o Carlos Santana consegue um decreto que autoriza o Sarney a passar o Inamps para o Ministério da Saúde. Waldir Pires então veta o decreto, dizendo que "o Inamps é um patrimônio dos trabalhadores e que por isso essa decisão deveria ser participada a eles".

Pensamos em fazer isso convocando uma Conferência. Mas, na época, as Conferências de Saúde eram espaços burocráticos, onde os temas e os resultados já estavam pré-definidos. Propusemos então convidar a sociedade para discutir a questão e realizar uma conferência com a participação de $50 \%$ de usuários. A VIII Conferência Nacional de Saúde conseguiu reunir, pela primeira vez, mais de 4 mil pessoas que trabalharam durante cinco dias consecutivos, produzindo relatórios diários e participando de uma assembléia final que durou mais de 24 horas. Da Conferência, sai o movimento pela Emenda Popular, a única emenda constitucional que nasce do movimento social. Esse foi o maior sucesso da Reforma Sanitária, que enfrentou mudanças de ministros e até de um presidente da República (o ex-presidente Fernando Collor, que era absolutamente contra o SUS). Para ele, segundo o pensamento da reforma neoliberal do Estado, o SUS era uma excrescência.

Como presidente da Fiocruz, vivenciei diretamente alguns desses fatos. Apresentei o documento Saúde e Democracia, presidi a VIII Conferência Nacional de Saúde, apresentei a Emenda Popular e, como Deputado Federal, fui designado como relator da extinção do Inamps. Todos achavam que era um suicídio, pois eu estava propondo a extinção de uma instituição com mais de cem mil funcionários e que iria mobilizar tanto trabalhadores quanto aposentados. De fato, sofri muita pressão. A surpresa é que, na hora da decisão final, as lideranças do Movimento dos Trabalhadores do Inamps eram favoráveis à extinção, em nome de um novo projeto.

\section{Radis}

Depois da VIII Conferência Nacional de Saúde, do texto da Constituição e do SUS implantado objeto da Lei Orgânica 8080 -, qual é o saldo de hoje?

\section{Sérgio Arouca}

Conquistamos a universalização na Saúde (o princípio constitucional que estabelece que todo brasileiro tem direito à saúde), definindo com clareza o dever do Estado e a função complementar da saúde privada. Conseguimos estabelecer que a Saúde deve ser planejada com base nas Conferências e conseguimos formalizar os Conselhos de Saúde como parte do SUS, tendo $50 \%$ de usuários. O último passo desse movimento pela Reforma Sanitária foi a formação da Comissão Nacional da Reforma Sanitária, que transformou o texto da Constituinte na Lei Orgânica 8080. Dessa forma, todas as propostas reformistas de esquerda viraram Lei e isso acabou possibilitando a aprovação de outros projetos da esquerda.

Era preciso abrir canais para que o pensamento crítico da área da saúde alcançasse uma expressão própria, dando início à formulação setorial de novas políticas públicas. De um lado, o SUS avança por meio das Conferências, dos Conselhos, da municipalização, da universalização dos direitos. Por outro, na operação do modelo assistencial, segue a lógica do Inamps. O Ministério da Saúde é organizado segundo este mesmo modelo do Inamps, segundo a lógica hospitalar, com estrutura medicalizante. A grande vitória é que a Reforma Sanitária cria novos atores na área da Saúde.

\section{Radis}

A Noas [Norma Operacional de Assistência à Saúde] representa progresso ou retrocesso na lei?

\section{Sérgio Arouca}

Nos últimos anos de gestão do José Serra, foram emitidos oito atos normativos por dia. Houve secretarias de Saúde que contrataram assessores para ler e interpretar esses atos, pois não davam conta de seguir essa fúria regulatória, que trata o Amazonas como o Rio Grande Sul, a Saúde da Família igual para todos, assim como o repasse de recursos. Passamos a ter a regulação como ênfase, com bons ou maus regulamentos. A Noas, por exemplo, é um bom instrumento de regulação que preenche a lacuna de esvaziamento do papel do nível estadual. Quando se perde o papel dos estados, se perde a possibilidade de planejamento regional. A Noas retoma o papel da municipalização, mas dá ênfase à questão da regionalização. A lacuna que ainda resta é que o 
conceito da Reforma Sanitária foi abandonado. Essa é minha briga atual. Nós temos que retomar o conceito da Reforma Sanitária, para retomar políticas dentro do sistema sem burocratizá-lo. Ele já foi burocratizado o suficiente.

\section{Radis}

Atualmente, qual é o pauta dessa luta?

\section{Sérgio Arouca}

Retomar os princípios básicos da Reforma Sanitária, que não se resumiam à criação do SUS. O conceito saúde/doença está ligado a trabalho, saneamento, lazer e cultura. Por isso, temos que discutir a saúde não como política do Ministério da Saúde, mas como uma função de Estado permanente. À Saúde cabe o papel de sensor crítico das políticas econômicas em desenvolvimento. O conceito fundamental é o da intersetorialidade. Não basta aprofundarmos cada vez mais o modelo 'Ministério da Saúde e Secretaria de Assistência à Saúde', temos que discutir saúde segundo políticas intersetoriais. O modelo assistencial é anti-SUS. Aliás, o SUS como modelo assistencial está falido, não resolve nenhum problema da população. Essa lógica transformou o governo em um grande comprador e todas as outras instituições em produtores. A saúde virou um mercado, com produtores, compradores e planilhas de custos. O modelo assistencialista acabou universalizando a privatização. O grande desafio que nós temos, imaginando o campo da oposição a esse modelo assistencial, é conseguir estabelecer um governo que tenha projeto e que não seja simplesmente um somatório de ministérios. Esse tipo de governo, onde sociedade, ministérios e secretarias são fraturados e onde cada um desses sujeitos compete com os outros, é uma falência.

\section{Radis}

Qual é o ambiente em que pode se dar essa luta? Sérgio Arouca

Primeiro, é preciso repetir que a 'inampização' do SUS nunca vai resolver os problemas da população. Eu estou propondo a convocação de uma Conferência extraordinária, cujo tema é a mudança do modelo assistencial do SUS, acabando com a Secretaria de Assistência à Saúde (SAS) e com o pagamento por prestação de serviços, que seria substituído por um contrato global com metas de desempenho, qualidade e prioridades definidas pela população. Podemos con- tratar o setor privado onde não existe o setor público, mas definindo prioridades e metas. O Programa Saúde da Família [PSF], por exemplo, pode ser entendido de duas maneiras. Ele pode ser simplesmente mais um programa paralelo, como no Rio de Janeiro, onde dez equipes de Saúde da Família não representam nada, ou pode ser um modelo reestruturante do sistema de saúde, no qual uma equipe dará atendimento personalizado às famílias segundo o conceito de desenvolvimento local, integral e sustentável.

É preciso que os programas de governo ganhem intersetorialidade nos municípios. É preciso trabalhar a questão da humanização da saúde. Um Projeto de Lei sobre os direitos do paciente rolou oito anos na Câmara, e eu não consegui aprovar. O projeto dizia simplesmente que o paciente tem direito aos seus dados e a optar por terapias, devendo ser tratado como cidadão - com nome e sobrenome.

Quando discutíamos a Reforma Sanitária e fazíamos crítica à prática da medicalização, já falávamos sobre a abertura às práticas alternativas de saúde, como a fitoterapia, a acupuntura e a homeopatia. O genérico é um avanço, mas só atende a quem já tinha acesso a medicamentos, diminuindo o custo. Cerca de 50 milhões de brasileiros não chegam nem aos genéricos. Por isso, é necessário estabelecer uma política que pense na fitoterapia e em hortas de produção de medicamentos naturais, que trabalhe com práticas de promoção e prevenção da saúde e que participe das discussões sobre Cidades Saudáveis.

\section{Radis}

Como você vê os avanços da tecnologia mundial de ponta, como a biotecnologia e os transgênicos?

\section{Sérgio Arouca}

Quando fui candidato a vice-presidente da República, com Roberto Freire, a bandeira da candidatura era a questão da revolução científicotecnológica. Essa revolução tecnológica tem a característica de transformar grupos humanos em descartáveis e até mesmo uma nação em algo descartável. Para se proteger da globalização, o Estado tem que ser forte e muito mais competente. Nossa pergunta era: "Como entrar na revolução científico-tecnológica?" Na nossa área, a resposta para essa pergunta seria a biotecnologia, pois nós temos uma das mais ricas biodiversidades do mundo. Nessa área de pesquisa, poderemos tra- 
balhar pela preservação e na produção de novos medicamentos, reagentes e novos alimentos, sem precisar de grandes aparatos técnicos. Do ato de protesto de José Bové - que é um conservador destruindo uma plantação de transgênicos no Brasil, só restou uma discussão maniqueísta e equivocada entre os que acreditam que a biotecnologia é solução para tudo e os que, vendo a biotecnologia como um demônio, querem proibir até a pesquisa. A biotecnologia é um enorme avanço, mas apresenta enormes riscos. $\mathrm{O}$ único experimento on-line em massa é a alimentação com transgênicos. Milhões de pessoas estão sendo submetidas a experimentos dos quais não se sabe o resultado e que não são controlados.

Há também um pensamento 'producionista', no campo da genética, querendo explicar que comportamento é determinação genética e esquecendo tudo o que já foi desenvolvido no campo da cultura e da antropologia. A vida é uma rede. Você está em contato permanente com vírus e bactérias que já vivem dentro do seu corpo e que fazem parte do seu DNA. O organismo humano tem a capacidade de produzir mudanças para sobreviver e essas mudanças são geradas segundo as influências do meio em que vive. Quando eu especializo uma planta, jogando sobre ela um único inseticida, qual será o impacto na rede da vida que está embaixo daquele solo? Para que eu possa interferir no DNA, eu utilizo uma bactéria como vetor para fazer a mudança, e as bactérias são seres vivos que também se modificam e se incorporam a seres mais complexos.

Dizer que a biotecnologia vai resolver o problema da fome é uma falácia. O problema da fome não está na produção de alimentos e sim na distribuição deles. A discussão tem que mostrar onde estão os avanços e onde a sociedade civil pode exigir o controle social. A energia nuclear era contida no laboratório e o risco era de haver uso político ou acidentes. A biotecnologia não tem paredes, ela está na rede da vida e exige, portanto, um controle social que não passa pelos pares da ciência. Está faltando uma Comissão de Bioética que tenha uma representação da sociedade e que não seja só de pesquisadores. Uma comissão que inclua também filósofos, pensadores e usuários. O Estado tem que se capacitar para esse mundo novo que nós estamos vivendo e a legislação brasileira não está nem chegando perto de começar essa discussão. Ela chegou à Lei de Biossegurança, mas não avançou. É preciso começar a discutir a questão da clonagem.

\section{Radis}

Hoje em dia, qual seria a política industrial para a saúde? Em relação às vacinas e aos medicamentos, a proposta ainda é ter autonomia na produção?

\section{Sérgio Arouca}

Estamos cada vez mais ligados a uma balança de pagamento em que é preciso ter o dólar, e por isso não podemos nos relacionar com o mundo globalizado sem estabelecer mecanismos de proteção. Precisamos de uma política de substituição de importação, que é possível, apesar da Lei de Patentes.

A saúde é uma área privilegiada, pois a grande maioria dos medicamentos não está protegida. Se hoje somos um dos maiores compradores de medicamentos do mundo, o Estado pode utilizar o poder de compra para fazer transferência de tecnologia, como fizemos com a [vacina] Sabin na Fiocruz: "Compramos vacina de sua empresa desde que você me associe, me transfira tecnologia e me capacite para produzir".

\section{Radis}

Existem parceiros possíveis de se associar?

\section{Sérgio Arouca}

Existem, sim. Em vez de entrar de uma forma suicida na ALCA, nós podemos nos associar a países com tecnologia de medicamentos. Isso significa fortalecer os laboratórios públicos. Eu não posso simplesmente permitir um fluxo de recursos e não atrasar o pagamento das bolsas de estudo se, quando uma pessoa termina o doutorado, não tem emprego. De que adianta mandar pessoas para o mundo inteiro para fazer mestrado e doutorado, se depois não são absorvidas? Paralelamente à política industrial, é preciso ter uma política agressiva na área da ciência e tecnologia. Em vez de ser um exportador de cérebros, o Brasil tem que ser um importador. Se quero profissionais em Biologia Molecular, preciso saber quem é que está trabalhando com isso no mundo e trazer para o país. A política em Ciência e Tecnologia não pode ser esta que a Capes e o CNPq oferecem. 


\section{Radis}

Independentemente de quem estará no próximo governo, de seus erros e acertos, quais são os principais desafios apresentados à sociedade?

\section{Sérgio Arouca}

Eu tenho participado de debates onde não se tem saída para nada. Mesmo no Conselho Nacional de Saúde, onde estive recentemente, as últimas perguntas que eu respondi manifestavam grande angústia. Este é um período crítico, em que presenciamos instituições internacionais perdendo espaço e Bush assumindo uniteralidade em tudo, tanto no comércio quanto na guerra. Você vê uma cultura guerreira. É uma coisa horrível o que está acontecendo nos Estados Unidos, é uma redução dos direitos humanos. O que está sendo feito lá é um tremendo retrocesso autoritário, digno de uma boa ditadura. Por outro lado, você tem pessoas que dão boas respostas. Eu acredito que as lutas pela cidadania, expressas na defesa do consumidor, na defesa de necessidades especiais, nas discussões sobre os direitos da mulher e dos novos temas envolvendo violência e saúde pública, estão ganhando força. O Ministério Público também propiciou enorme avanço na questão da cidadania. O desafio é dar conteúdo a essas questões.

O momento que estamos vivendo revela a paralisia do pensamento crítico nacional. O movimento sindical está paralisado e a universidade não tem feito nenhum debate crítico mais avançado. Isso exige que retomemos a Reforma Sanitária, enxergando o SUS a partir dessa reforma, e não vendo o SUS pelo umbigo do SUS. O umbigo do SUS vai apenas tentar regular o que está aí. Outro dia, ouvi um médico dizer com maior orgulho que tinha triplicado o número de amputações de diabéticos. Se o conceito é de produtividade e serviço, então ele amputa mais para ganhar mais. Para mim, isso é a falência. $\mathrm{O}$ conceito fundamental dessa última fase do SUS é o faturamento. Foi uma distorção na implantação do SUS.

\section{Radis}

Segundo a lógica de indução de mercado, quando pensamos em assessoria aos municípios, na formação profissional e nas universidades, há uma tendência de se direcionar pesquisas para onde há recursos.

\section{Sérgio Arouca}

De um lado, a universidade tem o papel de Estado, deve estar preocupada com gerações futuras, com conhecimentos novos e que não são privilegiados. Ela, no entanto, deve ter liberdade de atuação. Não pode estar subordinada a políticas de governo. De outro, o governo deve propor pactos à universidade. Nós queremos universidade aberta para vários tipos de curso. Posso pactuar com a universidade para o ensino à distância e treinamento dos quadros atuais que estão nos serviços. Se a pública não pactuar, pactue-se com quem faça, estipulando metas de desempenho e recursos. Desta forma, a universidade ganha uma dimensão de parceira do desenvolvimento. O Carlos Lessa [ex-reitor da UFRJ] diz que nós temos que voltar a desenvolver o corporativismo, no sentido de autonomia, permitindo-nos pensar além da política conjuntural de governo.

Em relação ao mercado, o governo Fernando Henrique congelou os salários de todo o setor público e começou a dar aumentos indiscriminados (dentro da Reforma Bresser) por áreas de atuação. O governo acabou criando induções, e a maior delas foi a do mercado de projetos públicos, envolvendo cada pesquisador individualmente em interesses personalizados. As instituições não têm mais projeto global, elas foram fragmentadas por baixo. Cada pesquisador precisa ter vários projetos individuais para ter acréscimo salarial e prestígio. Você acha que esse pesquisador vai querer participar de um projeto coletivo? Essa é a distorção máxima: o serviço público vendendo serviços para o próprio setor público. É a privatização do mercado que se fez por baixo, privatizando os desejos e as mentes das pessoas. Ela envolveu os prestadores de serviço, dizendo que o negócio é faturar, e os pesquisadores, dizendo que a coisa é projetar.

\section{Radis}

Como você analisa sua experiência parlamentar e suas experiências como secretário de Saúde?

\section{Sérgio Arouca}

Eu sou muito mais identificado como sanitarista da Fundação Oswaldo Cruz do que como militante político ou deputado, e é como eu me sinto bem. Outro dia, brincando com um amigo, eu disse que meu tempo de permanência em alguns cargos executivos nesses conflitos de poder tem diminuído radicalmente. Fui secretário de saú- 
de do estado do Rio durante nove meses, e meu período como secretário municipal caiu para quatro meses.

Como deputado federal, eu era líder de um partido de três. Isso foi um aprendizado fantástico, pois me permitiu atuar não só na área da saúde. Eu fiz a Lei do Sangue, a Lei de Saúde de Populações Indígenas, participei da extinção do Inamps e da defesa dos direitos do paciente, fui negociador da questão das patentes e das gratificações de desempenho e participei da reforma educacional junto com Darcy Ribeiro, entre outras coisas. Nesse campo, penso que já dei minha contribuição. Vou estar na política sempre, mas não volto a me candidatar. Sou muito mais sanitarista.

\section{Radis}

Em relação aos meios de comunicação, que caminhos você vê para a sociedade?

\section{Radis}

Eu acho que todas as experiências, em nossa área específica, têm tido sucesso. Nós temos o Radis, o Saúde em Debate, do Cebes, e as revistas da Abrasco, entre outras. Eu só tenho medo que, em algumas delas, o academicismo retire essa dimensão do pensamento crítico e a substitua pela 'lógica da epidemiologia' para aceitar artigos. Nós temos espaço, e a questão é como apresentar o debate. A discussão substantiva que o campo do pensamento crítico da oposição deve assumir é a mudança do modelo assistencial, retomando a Reforma Sanitária e reformando o SUS. Esse seria o diferencial e também a nossa grande unidade. A possibilidade de repensar o SUS como Reforma Sanitária pode ser nossa grande unidade.

\section{Nota}

1 Participaram da entrevista os jornalistas Ana Beatriz de Noronha, Caco Xavier, Daniela Sophia, Katia Machado e Rogério Lannes Rocha. 